\title{
Overview on Spammers' False Transaction and Comment in Chinese
}

\section{E-Commerce}

\author{
Qing Tian ${ }^{1, a}$, Jun-ling Zhu ${ }^{1, b^{*}}$, Hua-mei Sun ${ }^{1, c}$ \\ ${ }^{1}$ School of Computer Science, Zhao Qing University, Guang Dong 526061, China \\ aemail: zdtina@qq.com, ’email:zhuzhu000011@163.com, email: sunhuamei1973@163.com \\ ${ }^{*}$ Corresponding Author
}

\begin{abstract}
With the rapid development of Internet and electronic commerce, Internet spammers as well as their false transactions and comments frequently occur in the public media, which has become a major obstacle to the development of Chinese electronic commerce. In this paper, the author analyzes the current situation of Internet spammers' false transaction and comment in the field of Chinese electronic commerce, explores the attitude and policies of different big electronic business platforms to Internet spammer as well as their countermeasures. And finally the paper analyzes the reasons of Internet spammer proliferation in Chinese electronic commerce and puts forward countermeasures.
\end{abstract}

Keywords: E-Commerce, Internet Spammer, False Transaction, False Comment

\section{Introduction}

According to the thirty-eighth Statistical Report on Situation of China Internet Development of China Internet Network Information Center (CNNIC) in 2016, at the end of June 2016, the number of Internet users had reached to 710 million in China, the number of mobile phone users had reached to 656 million, the number of online shopping users reached to 448 million, in 2015 the annual online electronic commerce transaction had amounted to 3.8 trillion. In recent years, both China Internet and electronic commerce have developed in almost explosive way, which has created the Internet business empire one by one, which has also created a series of electronic commerce companies such as Alibaba, Tmall, Taobao, Jingdong, VIPSHOP, Dangdang, Ctrip, Qunar, Meituan, Dianping and so on. These companies have got rapid development in the network in the tide of Internet, which had become star enterprises in China Internet enterprises. However, under the halo of stars, these electronic commerce enterprises have gradually exposed some problems during the period of development, among them, Internet spammer, false transactions, false comments, fake products, fake tickets, problems of hotel occupancy and so on have emerged in an endless stream, which have become hot issues to media. On 2016 CCTV 3.15 Party, problems associated with Internet and electronic commerce industry accounted for more than $50 \%$ of the total party, which had shown us the field of electronic commerce have serious problem. Facing the end of the Internet network demographic dividend, Internet enterprises have to face an important issue, how to retain their customers and how to solve the problem of user loyalty, therefore, the integrity of the enterprise become an inevitable problem, however, with the Internet spammer that is formed in the period of barbaric growth, false transaction and comment has become the main obstacle to the integrity of the enterprise. 


\section{Overview of Internet Spammers’ False Transaction and Comment}

Internet spammer refers those who are driven by the commercial interests, aiming to achieve the improper purpose of affecting the network public opinion and disrupt the network environment through the operation of software robots or spammer groups, thus they can become the main network opinion producers who make and spread the false opinions and junk information and so on in the Internet. ${ }^{[1]}$ Internet spammer in the field of electronic commerce is a major part of Internet spammer, which can occupy the main part in the Internet spammer with the Internet spammer in the field of social communication. ${ }^{[2]}$ Compared with the Internet spammer in the field of social communication, Internet spammer in the field of electronic commerce are using false comments and advocating or spreading rumors on the target products, so as to form the orientation of public opinion for the target products, which can achieve the effect of affecting the users to make decision to purchase and doing harm to the interests of consumers, which can make the research on false comments recognition of Internet spammer in the field of electronic commerce appear more urgent, compared with the other Internet spammer such as the Internet spammer in the field of social communication. ${ }^{[3]}$

\section{Current Situation of False Transaction and Comment in the Field of E-Commerce}

False transaction and comment in the field of electronic commerce is the hardest hit of Internet spammer, as long as it is concerned with the behavior of online transaction that can make users consume or purchase, almost all the Internet spammer organizations can be seen, there may be slightly different in different industries. At present, there are a lot of electronic commerce websites that consumers are much more familiar with such as Taobao, Tmall, Jingdong and so on; as for the tourism websites, such as Ctrip, Qunar and so on; as for the catering websites, such as Meituan, Dianping and Ele.me and so on; as for film critic websites, such as Douban, Dianping, Meituan and so on; as for taxi software, such as Didi taxi, Uber and so on; as for App application download, such as Apple's App Store; as for the other O2O industry websites, such as door-to-door reservation service in 58.com including manicure, car washing and the other appointment service. Here it will take the following three areas as an example, namely, retailing electronic commerce, hotel accommodation, catering to discuss the situation of false transaction and comment in these areas, shown in Table [1].

We can see from the analysis of Table[1], false transaction and comment generally exists in the electronic commerce website, according to the transaction mode and evaluation standard of different platforms, as well as the platform policy and platform competition situation and so on, which can provide different propagation environment for the false transactions and false comments, some data are for looking good on the platform, so as to make false transaction and false evaluation freely issued, some are under the pressure of flow competition in the the platform environment, so the enterprises will take risks in order to get flow.

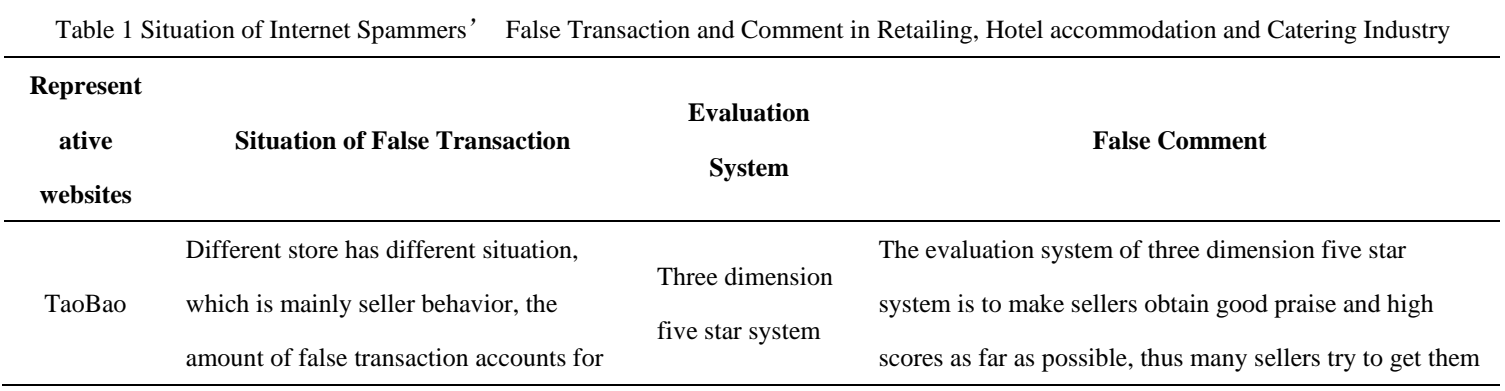




\begin{tabular}{|c|c|c|c|}
\hline & $\begin{array}{l}\text { a large part, which is the hardest hit of } \\
\text { false transaction. }\end{array}$ & & $\begin{array}{l}\text { through a variety of ways, such as brushing orders and } \\
\text { scapling praise and some other unfair ways to obtain } \\
\text { good reputation. }\end{array}$ \\
\hline Tmall & $\begin{array}{l}\text { Tmall stores are mainly manufacturers, } \\
\text { most of the shops have financial strength, } \\
\text { which would like to hire the professional } \\
\text { Internet spammer groups to maintain its } \\
\text { search rankings by means of brushing } \\
\text { orders in a great amount. }\end{array}$ & Five star system & $\begin{array}{l}\text { Roughly the same as Taobao, since it have no three } \\
\text { dimension evaluation system, so, as for the false } \\
\text { comment, it can make sellers better than that in Taobao, } \\
\text { which can make the evaluation more real. }\end{array}$ \\
\hline Jingdong & $\begin{array}{l}\text { Stores are mainly sellers, but some } \\
\text { platforms also take part in,particularly, } \\
\text { false transactions are mainly crowd } \\
\text { funding and auction, which has } \\
\text { repeatedly been reported by the media. }\end{array}$ & Five star system & $\begin{array}{l}\text { Comments on the proprietary trading product in Jingdong } \\
\text { can be more real, but on the platform there is a rule for } \\
\text { returning the scores to issue evaluation, which may exist } \\
\text { some factors to induce the consumers, while third party } \\
\text { seller is the same with Taobao. }\end{array}$ \\
\hline & $\begin{array}{l}\text { The platform is strictly monitored, most } \\
\text { of the products are Amazon FBA } \\
\text { products, the cost of brushing is high, } \\
\text { with small proportion. }\end{array}$ & Five star system & $\begin{array}{l}\text { Platform must crack down false comments strictly, } \\
\text { including induced praise, relatively the false comments } \\
\text { are fewer. }\end{array}$ \\
\hline Travel & $\begin{array}{l}\text { The hotel can be divided into three } \\
\text { categories, the first category is Ctrip } \\
\text { property trading: priority ranking; the } \\
\text { second category is Ctrip agent: artificial } \\
\text { agents; the third category is retailing. } \\
\text { Three categories of Ctrip as well as } \\
\text { merchants themselves are easy to join the } \\
\text { links of having false transaction. }\end{array}$ & five star system & $\begin{array}{l}\text { From these four dimensions, namely, location, facilities, } \\
\text { services, health to score, in addition, only checking in } \\
\text { can issue comments, thus, the reliability of evaluation is } \\
\text { relatively high. But there also exists the phenomenon that } \\
\text { issuing comments can return scores, therefore, the } \\
\text { platform may exist the induced behavior, which can } \\
\text { reduce the effectiveness of the evaluation. }\end{array}$ \\
\hline Qunar & $\begin{array}{l}\text { The situation is roughly the same as } \\
\text { Ctrip, in the case of the market share is } \\
\text { not as good as Ctrip, the degree of } \\
\text { having false transaction is even serious. }\end{array}$ & $\begin{array}{l}\text { Six dimension } \\
\text { five star system }\end{array}$ & $\begin{array}{l}\text { From these six dimensions,namely, facilities, health, } \\
\text { services, location, environment, dining to score, showing } \\
\text { the rating comments of the users, in addition, registering } \\
\text { can issue comment, users with no accommodation can } \\
\text { also issue comment, which can result in the proliferation } \\
\text { of false comments. }\end{array}$ \\
\hline Meituan & $\begin{array}{l}\text { According to the mode of group } \\
\text { purchasing, the operating space is large, } \\
\text { the amount of having false transaction is } \\
\text { great, while the sellers are in a leading } \\
\text { position, which has repeatedly been } \\
\text { reported by the media. }\end{array}$ & $\begin{array}{l}\text { Five point } \\
\text { system }\end{array}$ & $\begin{array}{l}\text { The level of users can be shown, only those consumers } \\
\text { who had consumed can issue comments, but there still } \\
\text { exist induced factors of evaluation, moreover, the } \\
\text { platform asked the evaluation must be specified to a } \\
\text { certain number so that they can earn points or be named } \\
\text { as careful evaluation, people who are regarded as having } \\
\text { careful comment can get } 100 \text { points, while } 500 \text { points can } \\
\text { be converted into } 5 \text { yuan as coupon. }\end{array}$ \\
\hline Dianping & $\begin{array}{l}\text { According to the mode of group } \\
\text { purchasing, the operating space is large, } \\
\text { the amount of having false transaction is } \\
\text { great, while the sellers are in a leading } \\
\text { position, which has repeatedly been } \\
\text { reported by the media. }\end{array}$ & $\begin{array}{l}\text { Three dimension } \\
\text { five star system }\end{array}$ & $\begin{array}{l}\text { Evaluation will show the level of users, the comments } \\
\text { come from three dimensions, namely, tasting, } \\
\text { environment, services to score, which can help users to } \\
\text { determine the effectiveness of evaluation information. } \\
\text { But it allows users with no consumption to issue } \\
\text { comments, which can result in the proliferation of false }\end{array}$ \\
\hline
\end{tabular}


From the false transaction events in recent years, which the media had exposed, we can find out that the society and ordinary consumers had learned more about the false transaction and false comments, which made each platform must adopt the corresponding measures to cope with the increasingly serious phenomenon of having false transaction and false comments.

In the following, we will take a few typical platforms as examples to discuss the countermeasures of the platforms.

Taobao and Tmall Platform

Taobao platform has strictly cracked down on false transaction and false comments, every year it has introduced a large number of counter measures according to the situation. In 2016, its false transaction penalties are as follows: 1. Credit of false transaction accounted for more than eighty percent of the credit account credit and the number of false transactions is more than ninety-six, each time it will minus ninety-six points; 2 . In addition to the conditions specified in the first item, credit caused by the false transactions accounted for more than fifty percent of credit accounts and the number of false transactions is over forty-eight, each time it will minus forty-eight points; 3 . The other false transactions, each time will minus twenty-four points. ${ }^{[4]}$

From February 15, 2016 to March 15, within a month, because of the alleged scalping problems, there were more than 220 thousand sellers that were sentenced to drop the level by Taobao as punishment. "Down the right" means that these shops can not fully display the opportunity, and the sellers that are cut down the right to synchronize, more than 390 thousand related brushing commodities must lower the right, the amount of the relevant sales must been cleared up from zero. At the same time, more than 6 thousand sellers were closed that had serious scalping behavior, more than 10 thousand sellers were sentenced to get penalty in different degree.

In order to deal with the false transaction, Ali Group has invested a lot in technology, so far it has developed a set of perfect inspection system, this system is composed of two systems, namely, the main evidence system and circumstantial evidence System. The main evidence system includes the following points: 1: When the Internet small number purchase, the corresponding computer IP MAC BIOS series SID, CPUID, and almost all of the hardware information and browser UA as well as some other software information. 2: The Internet small number should be bounded with the cloud server. 3: Real flow 4: The order number of logistics, once the system has a convicted item with non-compliance, it will be directly determined as the false transaction. Circumstantial evidence system: The statistical analysis of data on the store transaction can be the so-called dimension, such as the conversion rate, the repurchasing rate, the shopping cart proportion, the collecting rate, the condition of flow, the evaluating rate, customer per price, the proportion of the source of flow, once one or more than one dimension are over the the statistical rule of the system, which will be added and suspected as the false transaction order that can provide a chance to appeal for the sellers. Every day, the circumstantial evidence system will check for three times, the main evidence system will be investigated by Taobao irregularly, generally it will have investigation in three to fifteen days once the. ${ }^{[5]}$

From the above rules we can see that the inspection system of Taobao and Tmall adopts the compound method based on the users' comments, characteristics of users' behavior, the characteristics of users' relationship as well as the characteristics of users' using environment and so on. Moreover, the system is mainly inspected with machine itself, which is a inspection system that is based on a combination of monitoring and identification with semi supervised identification,its 
technical performance is in a leading position in identifying the false transactions and false comment in the field of electric commerce. ${ }^{[6]}$

\section{Jingdong Platform}

In order to cope with the increasingly serious problem of having false transaction, Jingdong platform especially introduced on-line system, called Hawkeye system in 2014, from 2015, the multi dimension inspection was carried on, if the seller in Jingdong open platform sales of goods or improve the shop score through improper means (i.e. "hype" behavior), impairing the interests of buyers' purchasing. Each tome it will minus 25 points. This type of " hype" behavior, including but not limited to the following forms: carrying on self purchasing and issuing self comment, maliciously changing price of the products, replacing goods, carrying on hype with the help of the third party, empty box and so on. False transactions through the improper means to improve the sales of goods or improve store ratings, thus Jingdong open platform has the right to delete the goods or delete the relevant stores' rating score.

As for monitoring false transaction, Jingdong started later than Alibaba, which mainly adopted the inspection method that is based on the users' behavior, the characteristics of users' relationship compounded with the characteristics of users' using environment, the main content of inspection including: user's account, user's account data, IP shop browsing, logistics information, the interval of placing order and so on, as for the effect of inspection, these inspection methods based on the users' behavior is not as good as that in the inspection system of Taobao and Tmall, but because of the number of businesses and some products are self-employed, thus the situation of brushing order exposed in front of the public is nt as good as that in Tmall and Taobao, but with the saturation of flow in Taobao, Tmall, the degree of having inspection is increased, the group of Internet spammer have a sign of transferring to Jingdong, a lot of groups of Internet spammer make research on the method of brushing order in Jingdong as well as the strategy of the countermeasures.

\section{Amazon Platform}

Amazon has strict requirement on false transaction and false comment, such as in the respect of having online shopping by means of brushing order, once it is found, the punishment will be very serious, the store is likely to be closed, the people who carried on the behavior of brushing order will be prosecuted, who will also accept the legal sanction. In the respect of having false comment, in addition to books, all categories of goods from the stores are no longer allowed to use "the substance induced comments" in Amazon, ReviewMeta is a technologies research corporation for the new policy of Amazon, which has found by using data analysis found that these "substance induced comments" are not objective. The average score of substance induced comments (accounting for $30 \%$ ) has 4.74 star, which is 0.38 star more than that of the non-substance induced comments (accounting for 70\%, 4.36 stars), therefore, the "substance induced comments" is prohibited.

In the respect of fighting against the false comments and ratings by using the technology of artificial intelligence plus big data model has been impressive, Amazon search ranking adopts logic of A9 algorithm, as for A9 itself, it has a strong anti brushing order feature. From MAC, IP flow, the conversion rate of products, the ratio of Review comment, residence time of buyers, the fresh degree of buyers account page, the tracking accuracy analysis of logistics information, as well as the other multi angles. Thus it can transfer the suspicious order to the special artificial investigation department through the smart analysis of the transaction data. In addition, Amazon introduced a new artificial intelligence machine learning system, it can give more weight to the speech after confirming the identity of the consumer, which also can display it in a more prominent position. If it is labeled as useful and timely comments by later consumers, it will get the corresponding weights. 
In addition, Amazon also takes entrapment scheme, some stores in Amazon are caught by brushing order, Amazon will send e-mail to the sellers, requiring them to make a decision whether to report the third brushing order l party team or reserve their stores.

Policy of other Platforms for False Transaction and Comment

Other platforms, such as Meituan, Ctrip, Qunar, Dianping and so on have also introduced the corresponding policies to face the increasingly serious situation of brushing order and media reports, however in the implementation of the policy, these platforms seem to be secretive, its enforcement degree and effect have not been announced. In addition, these platforms have large gap in technology compared with Taobao and Tmall platform, which is mainly based on the inspection method by using users' characteristics, the focus of inspection is also the information about IP address, user's name, the amount of orders, the frequency of placing order and so on.

From the above analysis, we can see that platforms have policies and measures of their own to deal with false transaction and false comment, but even so, false comments and false transactions still exist, with strengthening degree of the crackdown, false transaction and false comment have developed more specialized with groups or teams, who are not individually combat, they are well organized and planned in a operation team to fight with the policies of platforms.

\section{Reasons for False Transactions and False Comment}

In the Respect of Platform

Taking Taobao as an example, among the ranking weight of products in Taobao weight, the sales amount of products, DSR score, as well as the conversion rate is an important indicator, while these indicators can be completely controlled by brushing order. Stores can use this method to create a false sales coverage, so as to meet consumer's demand for the pursuit of sales and reputation evaluation. Compared to spending money on advertising, the way of brushing order is much faster and cheaper, the effect of which is also much better. In addition, at present, the market price of brushing an order is not single, generally from 3 Yuan to 10 Yuan for each order. According to Taobao's existing seller's scoring system,the number of order amounted to 300 with good praise then it can be a diamond seller, while the coast of is no more than 30 thousand Yuan. These stores need brush order only in the beginning of the business, after sales they can go on track. This is the reason why it is exposed by media for several times but it is still difficult to curb the momentum of development. On the basis of brushing order, when the buyers buy the product, in addition to looking at the details of the page, it is important to make the decision whether to buy by seeing the purchase of the users who have already bought to make the judgment. Therefore, sellers in order to improve or compete with the opponent, they will hire Internet spammer to buy the products, who also can ask then to issue some comments that can be beneficial to themselves, ${ }^{[5]}$ or who can use the way of rebating promotions and other information to guide consumers to make comments, even by harassing customers to force customers to issue good comments, all of these unfair evaluation methods are false comments.

In the Respect of Supervision

So far, due to the lack of the related laws for the transaction of electric commerce. Direct regulatory authority is the third party platform. In fact, in the whole process, both the supervision part and income part is the same side,which can make electric commerce be in an awkward position. On one hand, as the only part of regulator, the electric commerce part has an responsibility to detect and eliminate scalping behavior by brushing order. On the other hand, due to the loopholes of supervision, the internal staff can get certain benefits from brushing order. Therefore, during the process of supervision, this kind of situation that the internal staff brush order often occur. Taobao in 
the first bad period, the internal staff themselves will be involved in brushing order, recommending stores for consumers and improving ranking. Before the problem of brushing order was not exposed, platform was lack of appropriate supervision. After the problem was exposed, the platform had to have a certain amount of supervision. This kind of supervision is mainly based on random sampling. At the same time, the stores with unqualified sampling will be punished. At the end of last year, Jingdong had imposed on a large number of illegal businesses: severe penalties ranging from fines to prohibiting their goods, and even some stores were driven out. Even for scalping behavior of Jingdong made severe punishment for brushing order behavior, but because of the timeliness of sampling, it often lets scalping behavior come again. Moreover, because of the rapid development of electronic commerce platform, it has also increased the difficulty of management.

In the Respect of Technology

The Main Challenge of Inspecting Internet Spammers' Account:

Firstly, account of users has multi faceted feature, at present, taking Taobao account as an example, in order to deal with brushing order and issuing false comments, Taobao has issued a series of measures for account application and management methods, at present, the situation of account is basically stabilized, it is also based on this, the user's account is usually the normal using account for brushing order, therefore, there is a challenge for the monitor method that is based on users' characteristics.

Secondly, the amount of electric commerce users is huge, according to a report by Alibaba, so far, the amount of the registered users in Taobao has reached to 600 million, 407 million active users, each day there is a large amount of operating information, including browsing, collecting, shopping cart, purchasing, payment, evaluation information and so on. As for the detection of the abnormal accounts, it needs to be calculated for all the information with monitoring, so as to find the abnormal account. Thus, it is also a huge challenge.

Thirdly, there are professional organizations to study the countermeasures for the inspection of the system. Domestic websites, communication groups can play the role in organizing for the fictitious transactions, which are the biggest driving force behind the network for the fictitious transactions as well as the part for benefits, service can range from the flow of website, downloading amount of APP to the sales amount of electric supplier's products as well as ranking, they can issue a variety of comments by brushing order. According to the incomplete statistics, in 2015 the website that can provide service for the virtual trading has been more than 680, the amount of chatting groups and other communication groups has been more than 500, the annual flow of funds can be more than 200 billion Yuan, in the whole industry chain, the staff of having fictitious transactions can be amounted to 20 million, the value of fictitious transaction goods and services can be as high as 600 billion, such a huge industrial chain and participation people, which is the reason why false transaction and comment market is so active, when the new technology of preventing false transaction is emerged, these false transaction organizations will soon find a better way to escape inspection, as well as the inspection system, which can bring much bigger challenge for the detection system to deal with false transaction and false comments. ${ }^{[5]}$

Fourthly, the platform's ability of having different monitoring technology to seal with false transaction leads to the different situation of having false transaction, Alibaba as the largest e-commerce enterprise, it has been involved in the battle of fighting with false transaction, therefore it has made the maximum effort to deal with the false transaction in monitoring technical level, whose supervision ability is the strongest one, while the other platforms of electronic commerce have uneven levels of prevention and monitoring technology to deal with the false transaction that are not 
enough, which can easily lead to regulatory loopholes, bringing opportunities for false transaction and false comments.

\section{In the Respect of Law}

Electronic commerce is a new business platform, at the beginning period, it is a common means and marketing tool for the platform to attract users through false transactions, moreover, there is no strict rule both for legal or moral boundaries for adopting this kind of method, after the platform developed, this kind of brushing order behavior and evaluation way has got recognition from a part of enterprises or consumers, which is the reason to cause the continuous occurrence of false transaction and false comments. Although the relevant laws and regulations have been gradually improved, during the process of having judicial practice, as for false transactions and false comments, there still exists difficulties in getting evidence, setting up case, prosecutions, convictions as well as some other issues. Therefore, the feature of having small legal risk, with low cost of doing illegal deeds, who can get the fines from 10 thousand Yuan to 200 thousand Yuan at most. So far, in China there has not yet appeared criminal cases for brushing orders, so law can have no direct effective on brushing order teams. That is the reason why it can not play the role of dealing with the false transactions behavior, against only palliatives, which can not be conducive to fight against scalping behavior of brushing order.

In the Respect of Social Credit System

China Internet spammer behavior in the field of electric commerce is a special case, a single case individually, but with the whole social system together, the imperfect social credit system is its cause, in the current social system, there is no a complete set of method to regulate people's behavior, the cost of having illegal deeds is very low for people, even if it is convicted of having false transactions or false comments, it has almost no significant effect on personal credit, which will not affect the subsequent life. Therefore, there are many common consumers such as housewives and college students among them, ${ }^{[5]}$ who are the main body of the Internet spammer, involving themselves in the false transactions and false comments. Thus it can not be seen as a simple offense behavior because of such a large number of normal users have taken part in the false transactions groups, which should be a problem about the lack of awareness of the whole society and the lack of faith.

\section{Countermeasures of False Transaction and False Comment}

From the above analysis we can see that the key to occur the false transactions and false comments, in response to these problems, we can give the specific countermeasures.

From the perspective of platform, we can learn the experience from Amazon platform both in the efforts of technology and attitude, first of all, platform itself must have truly zero tolerance to the false transactions and false comments, which can not abandon its principle for the short-term benefits. Secondly, it must strengthen internal supervision, preventing collusion for having more serious false transactions. Thirdly, it must put efforts in the technology, which can identify the Internet spammer by using big data and artificial intelligence and other means so that it can let the Internet spammer have no living space.

From the perspective of supervision, according to the needs of rapid development of the electric commerce, country or industry needs to formulate the relevant regulatory measures according to the requirements of development, which can not let the platform itself become both the referee and the athlete. Moreover, platform must provide good service, improving technology, to strengthening the 
supervision of regulatory agencies to the platform, strengthening the degree of having the illegal crackdown, which can have no opportunity for the platform itself.

From the perspective of technology, both at home and abroad there are more and more studies on identifying the false transaction and Internet spammer, the researching results are more and more, therefore, each electric commerce platform should make full use of these research results, putting these results into the respect of the technology supervision of the platform, which can block the display stage of the Internet spammer from the perspective of technology.

From the perspective of law, as for false transaction and false comments in the legal level, they are illegal deeds, therefore, our country should increase the degree of legislation to solve the problem of having false transactions and comments in the field of electric commerce, which also must be firmly carried out in the actual application process. From the legal level to combat the damage to the interests of the vast number of consumers and the destruction of social behavior, so as to build the legal system of the Internet era.

From the 5.4 aspects of social credit system, to strengthen the construction of the social credit system, let each users, each citizen's action has received the social credit system of credit supervision, once reduced, will affect the future work, housing, loans and other aspects, to improve the cost of illegal person, let people consciously resist false trading and false evaluation behavior.

\section{Conclusion}

The Internet has been inextricably linked with our lives, false transactions and false comments seriously affect people's shopping experience, at the same time, it also affects the integrity of the consumer in society, which can hinder the further development of electric commerce. Therefore, we should make our efforts to improve the current Internet environment from various aspects, thus it is very urgent for us to establish a cleaner and healthier environment for electric commerce.

\section{Acknowledgement}

This research was financially supported by the National Science Foundation. Science and Technology Planning Project of Zhaoqing City, Project Number: $2015 B 010401003$

\section{Reference}

[1] Benevenuto F, Magno G, Rodrigues T, Almeida V. Detecting spammers on Twitter. In: Proc. of the 7th Annual Collaboration Electronic Messaging, Anti-Abuse and Spam Conf. (CEAS 2010), Vol.6. 2010. 1220. http://ceas.cc/2010/

[2] Wang G, Xie S, Liu B, Yu PS. Review graph based online store review spammer detection. In: Cook D, Pei J, Wang W, Zaiane O, Wu X, eds. Proc. of the 11th Int'l Conf. on Data Mining (ICDM2011). Washington: IEEE Computer Society, 2011. 12421247. [doi: 10.1109/ICDM.2011.124]

[3] Hayati P, Chai K, Potdar V, Talevski A. Behaviour-Based Web spambot detection by utilising action time and action frequency. In: Taniar D, Gervasi O, Murgante B, Pardede E, Apduhan BO, eds. Proc. of the Computational Science and Its Applications (ICCSA 2010). Heidelberg: Springer-Verlag, 2010. 351-360. [doi: 10.1007/978-3-642-12165-4_28]

[4] Liuqing Yang, Review the spam of Taobao network, New World,2015.5,72- 82.

[5] Ming Zhao, Review the spam phenomenon of Taobao, E-commerce, 2016.4, 30-33

[6] Ming Wu,Fang Ying ,Huian Chen. Analysis of the E-commerce spam industrial chain. China Management Informationization, 2015. 4(18), vol18.204-205 
[7] Mo Q, Yang K. Overview of Web spammer detection. Ruan Jian Xue Bao/Journal of Software, 2014,25(7): 1505-1526 (in Chinese). http://www.jos.org.cn/1000-9825/4617.htm

[8] Fei G, Mukherjee A, Liu B, Hsu M, Castellanos M, Ghosh R. Exploiting burstiness in reviews for review spammer detection. In: Kiciman E, Ellison NB, Hogan B, eds. Proc. of the 7th Int'l AAAI Conf. on Weblogs and Social Media (ICWSM 2013). Menlo Park: AAAI Press, 2013. 175-184.

[9] Liu X, the Impact of Spam Reviews on Purchase Intention of Consumer[D].Nanjing University, 2015

[10] DENG Song, WAN Chang-xuan, GUAN Ai-hao, CHEN Hui. Deceptive Reviews Detection of Technology Products Based on Behavior and Content, Journal of Chinese Computer Systems, 2015. 11 (11)Vol. 36 No11 2015, 2498-2503

[11] SONG Hai-xia, YAN Xin, YU Zhengtao. Detection of Fake Reviews Based on Semi-Supervised Active Learning, Journal of Kunming University of Science and Technology (Natural Science Edition). Vol. 40 No. 5 Oct. 2015, 59-65 